\title{
Norois
}

Environnement, aménagement, société

\section{In memoriam Gérard Moguedet (1946-2011)}

\section{Aziz Ballouche}

\section{(2) OpenEdition}

\section{Journals}

Édition électronique

URL : http://journals.openedition.org/norois/3706

DOI : 10.4000/norois.3706

ISSN : $1760-8546$

\section{Éditeur}

Presses universitaires de Rennes

\section{Édition imprimée}

Date de publication : 30 novembre 2011

Pagination : 179-180

ISBN : 978-2-7535-1765-3

ISSN : 0029-182X

\section{Référence électronique}

Aziz Ballouche, «In memoriam Gérard Moguedet (1946-2011) », Norois [En ligne], 220 | 2011, mis en ligne le 30 novembre 2013, consulté le 01 mai 2019. URL : http://journals.openedition.org/norois/3706 ; DOI : 10.4000/norois.3706

Ce document a été généré automatiquement le 1 mai 2019.

(c) Tous droits réservés 


\title{
In memoriam Gérard Moguedet (1946-2011)
}

\author{
Aziz Ballouche
}

1 Gérard Moguedet, premier vice-président de l'université d'Angers, nous a quittés dans la nuit du 6 au 7 octobre 2011, dans sa 66 année.

2 Finistérien d'origine et géologue de formation, Gérard Moguedet avait d'abord préparé et soutenu en 1973, à l'université de Nantes, une thèse intitulée Contribution à l'étude des sédiments superficiels du plateau continental de la Guyane française. Il s'est ensuite engagé dans la coopération internationale à l'université de Brazzaville, de 1974 à 1980, se consacrant à la fois à la formation des géologues africains et la recherche. De ce séjour africain, il tirera la matière de son travail de thèse d'État, sous la direction de Pierre Giresse, consacrée à une étude hydrologique, sédimentologique et géochimique des relations entre le fleuve Congo et la sédimentation récente sur la marge continentale entre l'embouchure de ce fleuve et le Sud du Gabon, et soutenue à l'université d'Angers en 1988.

3 À partir de 1980, sa carrière se déroule à l'université d'Angers, à laquelle son nom est si étroitement lié, essentiellement à la faculté des Sciences : d'abord au département de géologie, puis dans celui de géographie où il est nommé professeur en 1996. Dans la communauté des géographes, Gérard Moguedet était notamment reconnu comme expert des questions d'environnement et d'eau, avec une dimension à la fois régionale et internationale. Cependant, ce qui peut le mieux caractériser son profil est sa prédilection pour la transdisciplinarité.

4 Au niveau pédagogique, Gérard Moguedet s'est toujours impliqué dans une démarche de passage des frontières. Il a été l'une des chevilles ouvrières de la MST « Environnement », impliquant chimie, microbiologie et géosciences, autour des questions liées à la qualité de l'eau, ainsi que du Mastère Juturna spécialisé en «Évaluation Environnementale et conduite de projets ", en partenariat avec l'ESA (École Supérieure d'Agriculture d'Angers). Il a ensuite été l'initiateur du DESS « Gestion des zones humides » habilité en 2000 sous le double sceau écologie et géographie, devenu depuis le master d'éco-ingénierie des zones 
humides. Autour des questions d'environnement, et avec l'eau comme fil conducteur, il a toujours joué le rôle du fédérateur au sein d'équipes pédagogiques pluridisciplinaires, dans l'objectif de doter les étudiants d'une formation transversale et de compétences polyvalentes.

5 C'est aussi ce souci de dépasser les cloisonnements disciplinaires qui a prévalu dans son activité de recherche et d'animation scientifique. Il a ainsi créé, dès sa nomination comme professeur en 1996, le LSEA (Laboratoire des Sciences de l'Environnement et de l'Aménagement) qui affichait, dans son appellation même, cette volonté de fédérer des compétences multiples (géographie, hydrogéologie, chimie, agronomie...) pour répondre à des problématiques de recherche fondamentales et appliquées. Cette première étape dans la structuration de la recherche environnementale angevine, le conduit ensuite à fédérer le LSEA avec l'équipe d'écologie animale de l'université d'Angers et l'équipe de recherche en paysage de l'Institut National d'Horticulture d'Angers (INH) pour porter, en 2004, le projet d'une UMR « Paysage et Biodiversité » avec le ministère de l'Agriculture. Les adversités rencontrées ensuite par ce projet inclassable dans les grilles ministérielles ne l'empêchèrent pas de continuer inlassablement dans cette voie. Il disparaît au moment où son laboratoire intègre une des grandes UMR de géographie du Grand Ouest, sans perdre sa spécificité transdisciplinaire.

6 Enfin, on ne peut évoquer le parcours de Gérard Moguedet sans souligner son engagement collectif et son dévouement à la communauté universitaire. Responsable de formations, responsable de laboratoire, directeur d'UFR, vice-président d'université, il n'a jamais conçu ses responsabilités dans une logique de carrière mais comme des tâches collectives auxquelles un universitaire doit naturellement se consacrer. De la même façon, son implication et sa disponibilité constantes auprès des partenaires institutionnels, des collectivités territoriales et de la société civile dénotait une réelle volonté de pratiquer et de promouvoir une recherche au profit des territoires et des hommes.

7 Tant de tâches, toujours assurées avec une bonhomie, qui lui méritent amplement la reconnaissance de ses collègues, ses étudiants et toutes les personnes qui le côtoyaient, auront peut-être eu raison d'une constitution pourtant robuste. Il laisse au terme d'une vie trop courte l'exemple d'une existence joviale au service de l'intérêt général. 


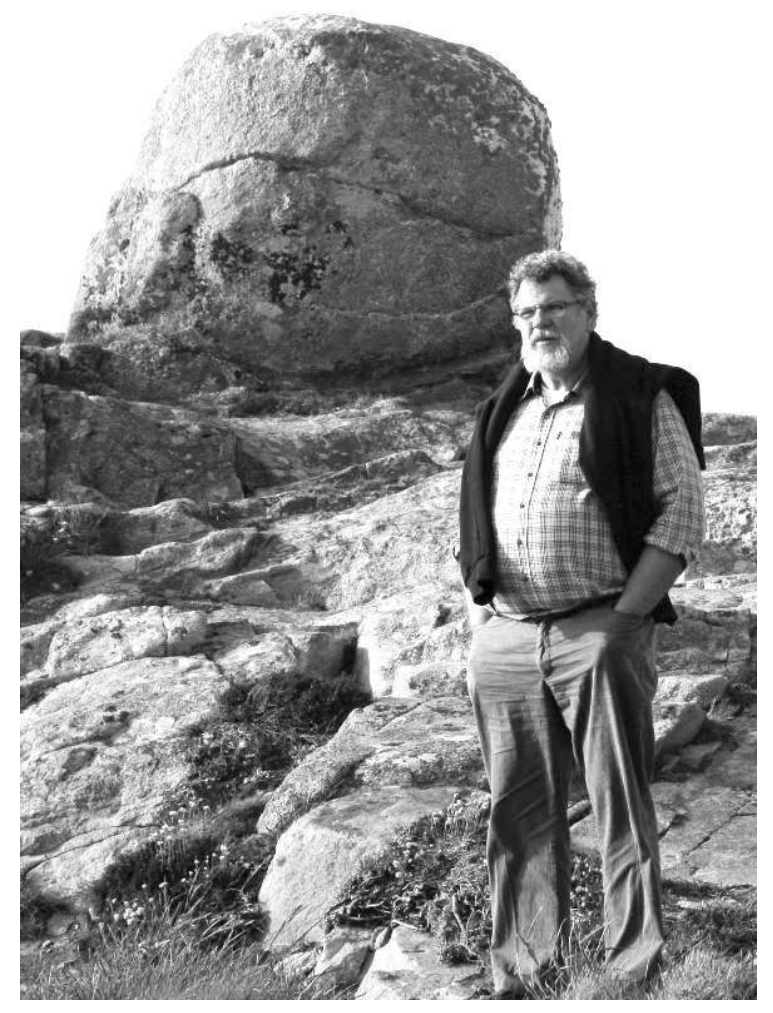

\section{AUTEUR}

\section{AZIZ BALLOUCHE}

Professeur de Géographie - Université d'Angers 